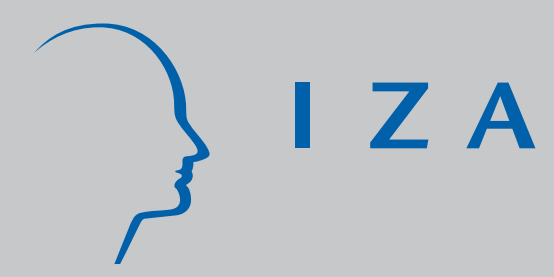

IZA DP No. 2281

Evidence of Ethnic Discrimination in the Swedish Labor Market Using Experimental Data

Magnus Carlsson

Dan-Olof Rooth

September 2006 


\title{
Evidence of Ethnic Discrimination in the Swedish Labor Market Using Experimental Data
}

\author{
Magnus Carlsson \\ Kalmar University \\ Dan-Olof Rooth \\ Kalmar University \\ and IZA Bonn
}

\section{Discussion Paper No. 2281 \\ September 2006}

\author{
IZA \\ P.O. Box 7240 \\ 53072 Bonn \\ Germany \\ Phone: +49-228-3894-0 \\ Fax: +49-228-3894-180 \\ Email: iza@iza.org
}

\begin{abstract}
Any opinions expressed here are those of the author(s) and not those of the institute. Research disseminated by IZA may include views on policy, but the institute itself takes no institutional policy positions.

The Institute for the Study of Labor (IZA) in Bonn is a local and virtual international research center and a place of communication between science, politics and business. IZA is an independent nonprofit company supported by Deutsche Post World Net. The center is associated with the University of Bonn and offers a stimulating research environment through its research networks, research support, and visitors and doctoral programs. IZA engages in (i) original and internationally competitive research in all fields of labor economics, (ii) development of policy concepts, and (iii) dissemination of research results and concepts to the interested public.
\end{abstract}

IZA Discussion Papers often represent preliminary work and are circulated to encourage discussion. Citation of such a paper should account for its provisional character. A revised version may be available directly from the author. 
IZA Discussion Paper No. 2281

September 2006

\section{ABSTRACT}

\section{Evidence of Ethnic Discrimination in the Swedish Labor Market Using Experimental Data*}

We present experimental evidence for recruitment discrimination against men with an Arabic sounding name. Our results show that every fourth employer discriminates against the minority. However, simulations indicate that ethnic discrimination is only responsible for less than one sixth of the native-immigrant unemployment gap. We extend previous analyses using this method by interviewing employers. We find that discriminatory employers have, to a greater extent, a male responsible for recruitment and a share of male employees greater than 35 percent. Firms that have an ethnic multitude plan were not found to discriminate less than other firms.

JEL Classification: J64, J71

Keywords: ethnic discrimination, exit from unemployment

Corresponding author:

Dan-Olof Rooth

Kalmar University College

39182 Kalmar

Sweden

E-mail: Dan-Olof.Rooth@hik.se

\footnotetext{
${ }^{*}$ We would like to thank participants at seminars in Kalmar, Gothenburg and Stockholm University for comments and helpful suggestions. Klara Johansson provided excellent research assistance. A research grant from the Swedish Council for Working Life and Social Research is gratefully acknowledged. The data used in the article are available from the authors upon request.
} 


\section{Introduction}

In 2002, foreign-born individuals composed twelve percent of the total population of Sweden. Analyzing the labour market situation of these immigrants indicates integration problems that are concentrated to the recruitment process. Unemployment rates were found to be relatively high for many immigrant groups when compared to natives, especially for groups that have immigrated to Sweden from countries outside Europe. However, income differences compared to natives are more or less negligible if employed in the same sector and working full time. One possible explanation for native-immigrant differences in labour market outcomes is ethnic discrimination. Another is (to the researcher) unobserved productive "Swedish-specific" characteristics, such as language skills. To distinguish between these two explanations, i.e. to identify the extent of ethnic discrimination, is difficult using register data since not all differences in productive characteristics are accounted for.

Making inference about ethnic discrimination from interview data is also problematic for various reasons. Minority members may overstate or understate the degree of discrimination. When considering interviews with employers they don't necessarily express their true attitudes towards minorities and even if they do their attitudes are not automatically consistent with their behaviour. Hence, due to the shortcomings of traditional register and interview data and the inconsistency between attitudes and behaviour, it is clear that experimental methods are required.

Internationally, different forms of field experiments have been used to test for discrimination specifically in recruitment (see Riach and Rich, 2002). Correspondence testing implies that the researcher sends two equal applications to 
advertised job openings with the only difference being the name of the applicant; one with a native sounding name and the other a foreign sounding name. Ethnic discrimination is quantified by the difference in the number of call backs for interview between the two ethnic groups. A great number of situation tests have been conducted in Europe and the US during the preceding decades and a clear majority of studies find discrimination against minorities (see Riach and Rich, 2002, for a summary of these experiments).

There are reasons to expect that discriminatory behaviour exists among Swedish employers. Longitudinal attitude surveys of the general public show evidence of negative attitudes toward immigrants in general (FSI, 2004) and surveys among potentially discriminated groups also point in this direction (Lange, 2000). Further, most quantitative studies of the phenomenon find that ethnic discrimination exists and is extensive (Arai and Vilhelmsson, 2004, le Grand and Szulkin, 2002, and Rooth, 2002). However, contradictory evidence does exist. Åslund and Rooth (2005) did not find any evidence that the unexpected events of 9-11 had a more detrimental impact on the labour market opportunities of immigrant groups that were exposed to increasingly negative attitudes (see also Edin and Lagerström, 2004).

Using the correspondence testing method our field experimental data was collected between May 2005 and February 2006 by sending applications to job openings in thirteen different occupations in the Stockholm and Gothenburg labour market areas. In total we replied to 1,614 job openings. In 527 cases at least one of the two applicants were invited for interview. It was then found that 29 percent of all employers discriminated against the male with the Arabic sounding name. Interestingly, despite the fact that low level occupations have the largest share of immigrant employees we found that discrimination is more prevalent in lower level 
occupations than in higher level occupations. We also interviewed employers asking questions highlighting selection processes in recruitment decisions. These results indicate favouritism towards the Swedish male.

The remainder of this paper is outlined as follows. Section 2 presents the methodology used and the design of the experiment. Section 3 describes the collected data. Next, a simulation of the native-immigrant unemployment gap is performed in section 4. In section 5 an analysis using interview data on what characterises a discriminatory firm is performed. The final section concludes the paper.

\section{Correspondence testing - the method and design ${ }^{4}$}

Situation testing usually includes correspondence testing as the first step; this is then followed by audit testing. This study is a correspondence test using written applications although neglects the second (audit) step where real persons are sent to interview. The correspondence test is performed by having two equally productive individuals belonging to different ethnic groups apply for the same job through a written application. The employer's response can be: both invited for interview, no one invited or only one individual invited. If both individuals are invited they are treated equally. If neither is invited it can be tempting to view it as equal treatment as well. However, in reality we don't know if the applications even reached the employer and were examined. The International Labour Organization (ILO) suggests disregarding cases where neither is invited whereas the Urban Institute (UI) treats neither-invited as an observation of equal treatment. Including cases

\footnotetext{
${ }^{4}$ See Riach and Rich (2004) for a discussion on ethical considerations of the method.
} 
where neither is invited gives a lower bound, while excluding them gives a higher bound for the discrimination measure.

In the case where only one individual is invited discrimination is potentially observed. However, it is important to notice that the two applicants can be treated unequally also due to random factors. Due to the risk of being discovered we could not send both applications simultaneously, typically they were sent one day apart. Perhaps, for whatever reason, all applications received by the employer on the first day are viewed negatively, while on the second day all incoming applications are treated more positively. In these instances we will observe unequal treatment which is not systematic. Hence, we must take into account such random factors when calculating the degree of discrimination. By assuming that unfavourable treatment which randomly occurs is equally frequent for both the majority and minority groups the net discrimination measure can be used, which is proposed by the ILO, as well as the UI. The net discrimination measure is obtained by subtracting the number of cases where only the minority is invited from the cases where only the majority is invited, to cancel out random cases, and then divide by the number of usable tests. That is,

Net Discrimination $=\frac{\text { Only majority invited }- \text { Only minority invited }}{\text { Number of usable tests }}$

Before proceeding it should be pointed out that the correspondence testing method has been criticised, see for instance Riach and Rich (2002). We would like to address some of that criticism. First, the collected vacancies are not representative of the labour market as a whole, i.e. not a random sample of companies, and it only 
addresses discrimination using formal applications. Hence, it is a partial analysis of the labour market. Second, the method does not include the final job offer stage and does not investigate who actually gets the job, which after all is what we are interested in. However, the discrimination that occurs in the final stage of the recruitment process is approximately only 10 percent in the studies presented by Riach and Rich (2002, own calculations). It is then mainly determined at the early stages of the recruitment process which individual will be given a chance to get the job. Hence, given these shortcomings the method should be viewed as a complement rather than as a substitute to register and interview data. Finally, as demonstrated by Heckman (1998), the experimental design does not identify the extent of taste discrimination exclusively. ${ }^{5}$ Observed discrimination can also occur if employers use group information when evaluating applications, i.e. statistical discrimination is at play. For instance, employers can have stereotypes about certain groups which will be triggered and acted upon when reading the name of the applicant even if the applications themselves are of identical quality.

\subsection{Design of the experiment}

The experiment was conducted between May 2005 and February 2006. During this period all employment advertisements in chosen occupations found on the webpage of the Swedish employment agency were collected. ${ }^{6}$ All in all, 3,228 resumes were sent to 1,614 employers. Call backs for interviews were received via telephone, email

\footnotetext{
${ }^{5}$ Some recruitment experiments have tried to identify statistical discrimination, see Bertrand and Mullainathan (2004) and Weichselbaumer (2003).

${ }^{6}$ However, in approximately $20 \%$ of the job openings it was not possible to apply with email. These vacancies were excluded.
} 
or ordinary post. To minimize inconvenience to the employer invitations were promptly declined.

\section{Choice of occupations}

The experiment was restricted to thirteen occupations and the two major cities of Sweden; Stockholm and Gothenburg. The included occupations were both skilled and semi/unskilled occupations and included a relatively high as well as low ratio of immigrants. $^{7}$ To make satisfactory progress in the collection of cases it was necessary that the demand for labour was high in the chosen occupations (Table 2 presents details for the selected occupations).

\section{Construction of resumes}

The resumes, consisting of a short letter and a $\mathrm{CV}$, had to be realistic yet still not belong to any real persons. They had to signal the same level of qualification and since the competition from other applicants was considerable, the testers had to be well-qualified. A number of written applications available on the webpage of the Swedish employment agency were used as templates and adjusted and calibrated. ${ }^{8}$ For each job category a number of resumes were constructed in order to yield a pool to select from at random. To each resume a name, an email address, a telephone number and a postal address was attached as well.

The choice of names was crucial since ethnicity is only signalled through the name. Fortunately, there is a clear distinction between typical Swedish names and

\footnotetext{
${ }^{7}$ This information was taken from the occupational register, Statistics Sweden, 2003.

${ }^{8}$ Applicants were 25-30 years old and had two to four years of work experience in the same occupation as the job applied for. The application consisted of a short biography on the first page and a detailed CV of education and work experience on the second page, see Carlsson and Rooth (2006) for an example.
} 
Arabic names. Three of the most frequent Swedish and Arabic names occurring in Sweden were selected and these were randomly assigned to resumes in order to avoid name effects. ${ }^{9}$ An email address and a telephone number (including an automatic answering service) were registered at a large internet provider and a phone company for each fictitious applicant. To prevent any invitations being lost or returned to the employer postal addresses were also included in the resumes. The addresses were chosen to signal that the respondents lived in the same neighbourhood. The constructed resumes, being randomly assigned a name and contact information, were then sent to the employer in alternating order with a one day delay in between.

\section{Data collection}

The last row of Table 1 shows the aggregated results and from the second column it can be read that applications were sent to 1,614 different job openings. The third column shows that in 1,087 cases neither individual was invited for interview. In the remaining 527 cases (column 4) at least one was invited. In 240 cases (column five) both were invited (equal treatment), in 221 cases (column 6) only the "individual" from the majority group was invited and in 66 cases (column 7) only the "individual" from the minority group was invited. Hence, net discrimination against the minority, as defined by ILO, can be read from the last two columns and is 155 cases or 29 percent. The net discrimination measure proposed by the Urban Institute is 9,6

\footnotetext{
${ }^{9}$ We used the Swedish first names Erik, Karl and Lars and the last names Andersson, Pettersson and Nilsson and the Arabic first names Ali, Reza and Mohammed and the last names Ameer, Hassan and Said, from the name statistics register, Statistics Sweden (2005). A sensitivity analysis showed that different names and resumes had no statistically significant effect on the probability of being invited. These results are available upon request.
} 
percent $(155 / 1,614)$. The "true" measure of discrimination is then bound in between these two extremes. Table 1 also gives the same type of data description for each of the 13 job categories separately. Net discrimination was not found to be statistically different in the Stockholm and Gothenburg labour market areas.

$* * *$ Table 1 about here $* * *$

Interesting results are revealed when calculating correlations between the net discrimination measure, the percentage of immigrants employed, the percentage of females employed and the skill requirement in the occupations (see Table 2 for the data). We found that net discrimination and the percentage of immigrants employed in the occupation are positively correlated (0.64 and statistically significant). The interpretation is that firms with a higher percentage of immigrants employed discriminate against the minority group to a greater extent. A possible reason why these firms still employ immigrants might be because few majority group members look for jobs in these occupations/firms. When these firms are then confronted with a majority and minority applicant the preference is given to the majority. Second, the correlation between net discrimination and the percentage of females is negatively correlated, but insignificant. Hence, there is a tendency that occupations with a greater percentage of females discriminate less. ${ }^{10}$ Third, there is a negative correlation (-0.77 and statistically significant) between net discrimination and the occupational skill level implying that there is less discrimination in highly-skilled occupations. One explanation for this finding may be that highly skilled job tasks

\footnotetext{
${ }^{10}$ This becomes evident within sectors in the analysis of section 5 .
} 
are often very specific in nature and, hence, individual productivity is more evident from reading a highly skilled individual's application when compared to a low skilled individual's application. Bovenkerk et al. (1995) and Goldberg et al. (1996) find similar results for Holland and Germany respectively, i.e. a higher level of discrimination occurs in low and semi-skilled jobs compared to high-skilled jobs.

\section{*** Table 2 about here $* * *$}

As mentioned before the presented results are not necessarily representative for the labour market as whole or for different time periods. For example, the level of discrimination may change with the state of the macro economy. In times of recession labour market discrimination may be higher due to an excess supply of labour. Ideally, one would like to repeat the experiment under different states of the economy. However, our data allows us to shed some light on the impact of macro effects using another approach. If we allow the response rate for natives to proxy for labour demand in different branches then a high response rate indicates a high demand for labour. We find a negative, and statistically significant, correlation between net discrimination and the response rate indicating a higher level of discrimination when labour demand is low relative to the labour supply. Since our investigation was conducted during an upturn of the economy we might underestimate the average degree of discrimination. However, this result may be 
purely spurious if both discrimination and response rates are determined by other branch specific variables. ${ }^{11}$

\section{Simulating the native-immigrant unemployment gap}

Using the collected data in a simulation exercise we can answer the question: what would be the unemployment rate of immigrants given that the only difference when compared with natives is the call back rate? This simulation, using the standard job search model presented in Mortensen (1986), will indicate how much of the nativeimmigrant unemployment gap can be explained purely by ethnic discrimination.

The focus of the job search model is on an unemployed person who strives to maximize the present value of lifetime income. The person knows the distribution of wages offered but not where offers are located. For simplicity, we assume that search intensity is the same among natives and immigrants. ${ }^{12}$ Hence, the job searcher can not affect how often offers arrive. The job searcher decides an acceptance wage that maximizes the present value of lifetime income. He continues to search until a satisfactory job offer is received. One can incorporate discrimination into this model by assuming that the job offer arrival rate differs between the ethnic groups. If a significant share of employers are reluctant to hire certain immigrant groups, this can be seen as a decrease in the job offer arrival function.

In this type of job search model the escape rate out of unemployment is $\theta=\lambda * \eta$, where $\lambda$ is the function for job/wage offer arrivals and $\eta$ the job/wage offer acceptance rate. We assume that job offer arrivals are proportional to our observed call back

\footnotetext{
${ }^{11}$ For example, we find a significant correlation between occupational category and response rates as well.

12 This also seems to be the case in reality as shown by Olli Segendorf (2005).
} 
rates $(\varphi)$ with a fraction $\mathrm{p}$, i.e. $\lambda=\mathrm{p}^{*} \varphi$, and that $\mathrm{p}$ and the wage offer acceptance rate is the same among immigrants and natives. ${ }^{13}$ If we assume that the hazard rate out of unemployment follows an exponential function the expected duration of unemployment is $1 / \theta .{ }^{14}$ Finally, the unemployment rate can be calculated as $\mathrm{u}=\mathrm{f} / \theta$, where $\mathrm{f}$ is the inflow rate into unemployment, which is assumed to be the same among immigrants and natives, i.e. no discrimination in firing. Hence, we assume that immigrants and natives are equal in all other respects except for the job offer arrival rate/call back rate. It is then easily found that the relative unemployment rate for immigrants $\left(u_{I} / u_{N}\right)$ is equal to $\varphi_{N} / \varphi_{I}$. The simulated unemployment rate of immigrants is then $u_{N} *\left(\varphi_{I} / \varphi_{N}\right)$, which is then contrasted to the observed immigrant unemployment rate.

Information on native and immigrant unemployment rates by the level of education is taken from the Labour Force Surveys. In the note to table 3 it is found that the relative call back rate is 1.53 when all occupational categories are merged, 1.38 for highly skilled occupations and 1.69 for lower level occupations. The predicted unemployment rate for immigrants is 5.9 percent when the only difference to natives is in the call back rate. Hence, the results indicate that the lower call back rate due to discrimination accounts for one sixth of the observed native-immigrant unemployment gap. ${ }^{15}$ For highly skilled immigrants ethnic discrimination can explain about 9 percent (1.2/13.5) and for low skilled immigrants about one fourth of

\footnotetext{
13 The same $\mathrm{p}$ for immigrants and natives assumes that there is no discrimination in the last stage of the recruitment process. This assumption is supported by international audit studies finding a very small discrimination effect at this last stage, see Carlsson and Rooth (2006).

14 This assumption makes the calculation simple, but is also to some extent supported by results for Sweden, see for instance Carling et al (2001).

15 Discrimination explains the difference in the unemployment rate between 5.9 and 3.9 percent, or approximately one sixth of the total unemployment gap, i.e. $(5.9-3.9) /(16.2-3.9)=0.16$.
} 
the unemployment gap (2.9/12.2). Our simulation results suggest that even if discrimination exists, as long as there are enough non-discriminatory firms, discrimination will not manifest itself into radically higher unemployment rates for the discriminated group. Even if our simulation is based on an immigrant that is very similar to a native in productivity, it indicates that other factors are important for selective recruitment decisions. One such factor is that immigrants on average lack "Swedish-specific" characteristics, such as language skills.

$* * *$ Table 3 about here ***

The accuracy of the simulation, of course, hinges on how well the used assumptions correspond to reality. For example, if there is extensive discrimination prevalent at the job offer stage, or in firing, we will underestimate the part of the gap being explained by discrimination. If the job/wage offer acceptance rate is in fact greater for immigrants (in order to compensate for potential discrimination) we will instead overestimate the gap being explained. Finally, and most importantly, the simulation will most likely give a lower bound on to what degree discrimination explains the unemployment gap towards natives since the hypothetical immigrant used in the experiment is very similar to the average native. Hence, if we could identify the call back rate of "worse-off" immigrants, net of any productivity differences, possibly a larger extent of the gap will be explained by differences in call back rates, i.e. ethnic discrimination. However, net discrimination would not change whether using first or second generation immigrants, if, for instance, the discrimination is purely due to taste with the employers acting upon ethnic belonging. 


\section{Survey results - who discriminates?}

We interviewed employers that invited at least one applicant for interview. 371 employers participated in the survey, i.e. a response rate of approximately 70 percent. An analysis of non-participants versus participants showed that the extent of discrimination was as high in both groups indicating that the sample is not selective in this respect.

Every subject was asked eleven questions which were transformed into eleven new variables used in the analysis in this section. ${ }^{16}$ These explanatory variables can be divided into five categories (see also Eq. 2); the composition of employees (the share of male employees ${ }^{17}$, the share of employees born in or outside Europe ${ }^{18}$ and personnel turnover, i.e. the number of new recruitments relative to the number of employees at the firm), responsibility in the recruitment decision (sex and ethnicity of the person with (highest) responsibility for recruiting personnel and whether the firm has a personnel department for recruitment), having a plan for equal rights with respect to sex and/or ethnicity, the $\operatorname{size}^{19}$ of the firm, and whether the firm discriminated against Swedish females (being one if only the majority male was invited for interview but not the majority female). This latter variable was available since we also sent a third resume signalling a majority female, i.e. a female with a

\footnotetext{
${ }^{16}$ See Carlsson and Rooth (2006) for an extensive description of the survey

${ }^{17}$ This original variable was found to be correlated with the dependent variable in a non-linear way with a "switch" just around a male share of 35 percent. Hence, we transformed this variable into a binary variable being one if the firm's male share was higher than 35 percent and zero otherwise.

${ }^{18}$ These originally continuous variables were recomputed into binary ones with either (i) having no employees, (ii) having 1-10 percent, or (iii) having more than 10 percent of the employees born in or outside Europe, respectively.

${ }^{19}$ This original variable was found having a "switch" just around 100 employees. We found no difference in the estimates for firm sizes below that threshold, i.e. between, for example, five of fifty employees.
} 
Swedish name. ${ }^{20}$ The correlation between the respective category of explanatory variables and the probability of being a discriminating firm is given by parameter vectors $\beta_{1}$ to $\beta_{5}$. Vector $\beta_{6}$ includes occupational and public sector fixed effects. The model being estimated can then be expressed as:

Discr $=\beta_{0}+\beta_{1} *$ Composition of employees $+\beta_{2} *$ Responsibility characteristics $+\beta_{3} *$ Equal Rights $+\beta_{4} *$ Size of firm $+\beta_{5} *$ Discriminates female $+\beta_{6} *$ Occupation

The dependent variable is a binary variable being one if the firm only invited the majority for interview and zero otherwise. Under the hypothesis that no ethnic discrimination occurs against the majority "both called for interview" and "only the minority called for interview" are assigned a zero. Observed unequal treatment against the majority, i.e. only the minority being called, is expected to have been caused by random events. ${ }^{21}$ Random events could also be the explanation as to why some firms only call the majority, and hence, we will incorrectly categorize these firms as discriminatory ones. By not separating random event cases from discrimination cases the level of "discrimination" will differ from the net discrimination measure in section 2 (where random cases were cancelled out). The measure of discrimination in the regressions then becomes

\footnotetext{
${ }^{20}$ See Carlsson, 2006, for further details

${ }^{21}$ The characteristics of firms treating the two applicants equally and those only inviting the minority should then not differ since they are all non-discriminating firms. We tested and found support for this assumption by excluding firms/cases only calling the majority for interview and estimating regressions assigning firms only inviting the minority for interview a one and being zero otherwise. The group of employers calling only the minority for interview was not found to be significantly different from firms calling both applicants for interview, see Carlsson and Rooth (2006) for these results. Another possibility is to exclude firms/cases where only the minority is called. This procedure did not change the estimates in Table 6 below, but increased standard errors. Therefore "only minority called" cases were included and treated as zeroes.
} 
Discrimination $=\frac{\text { Only majority invited }}{\text { Number of usable tests }}=\frac{150}{371}=40.4 \%$

Table 4 shows the means of the explanatory variables (first column) and the estimated marginal effects from a probit regression of Equation 2. Model 1-4 estimates the parameters $\beta_{1}, \beta_{2}, \beta_{3}$ and $\beta_{4}$, respectively, without controlling for any other variables, while Model 5-8 estimates the same parameters but with controls for occupations and public sector (fixed effects). In Model 9 we include all variables simultaneously, but without controls for occupation. The estimates do not change when compared to being inserted one at a time. In Model 10 we also control for occupation and public sector. By comparing Model 9 and 10 it becomes clear that most variation in discriminatory behaviour is within occupations and not between them. ${ }^{22}$

Model 10 states that discriminating firms are composed of at least 35 percent male employees, a person responsible for recruitment that is male, less personnel turnover, a plan for equal rights with respect to gender and less than 100 employees. The last model, Model 11, also includes the variable indicating whether the firm discriminates against majority females. This estimate is positive and significant and the interpretation is that if a firm discriminates against females then there is a higher probability that it discriminates against the ethnic minority as well.

\footnotetext{
${ }^{22}$ The correlation between net discrimination and skill requirement was calculated in section 2 . When adding the skill requirement variable from Table 2 to Model 9 this correlation is still highly significant with an estimate of -0.36 for high as compared to low and medium-skilled occupations.
} 
These results suggest that the kind of discrimination we observed is nepotism. We found that majority ${ }^{23}$ males responsible for recruitment discriminated to a greater extent than females and also that firms discriminating against the minority male discriminate against the majority female as well. Hence, the majority male chooses someone from his own group rather than excluding someone from another group.

$* * *$ Table 4 about here ***

\section{Conclusion}

This study is the first for Sweden examining the extent of ethnic discrimination using correspondence testing. With the ILO measure of discrimination, using only cases where at least one individual is invited, we found a net discrimination of 29.4 percent against the applicant with an Arabic-sounding name. An alternative measure of net discrimination, as proposed by the UI and using all cases, we found that 9,6 percent of the firms were discriminatory. The true measure of discrimination, within the selected firms, is bounded by these two extremes. We also found that discrimination is higher in low compared to high-skilled occupations, which is in line with results from Holland and Germany.

Unfortunately, the net discrimination measure does not in itself provide any guidance as to what extent discrimination explains the native-immigrant unemployment gap. Therefore we simulated, within a search model framework, what the unemployment rate of immigrants would be given that the only difference

\footnotetext{
${ }^{23}$ There are very few minority males responsible for recruitment in firms.
} 
to natives is in the call back rate, which we observed. These results indicate that discrimination is only responsible for about one sixth of the native-immigrant unemployment gap. Hence, unobserved characteristics such as language skills and other Swedish specific characteristics on the supply side could be important in explaining the remainder of the unemployment gap.

Previous analyses using this experimental method have not attempted to answer what characterizes a discriminatory firm. We have extended the method by interviewing employers that invited at least one applicant for interview. We found that employers that discriminate to a greater extent have a male responsible for recruitment, a share of male employees greater than 35 percent and that firms who discriminate against females have a higher probability of discriminating against ethnic minorities as well. This suggests that the type of discrimination we observed is nepotism. Majority males choose someone from their own group rather than excluding individuals from other groups.

Further, we find that firms with more than 100 employees and firms with a higher personnel turnover discriminate less. There may be several reasons for this. Large firms and firms with a higher personnel turnover may have a more comprehensive recruitment process making statistical discrimination smaller. Another explanation might be that these companies use recruitment practices that call more individuals to interview, i.e. on average decide to call all (both) applicants with similar merits above a certain threshold.

The observation that larger firms and firms with higher personnel turnover are less discriminatory may have an impact on the estimated level of discrimination. Firms that had many job openings during the period of investigation were included 
only once. Hence, firms with many job openings will have a lower weight in our sample compared to their weight in employing people in the labour market.

Interestingly, firms with an ethnic multitude plan were not found to discriminate less and those with a gender multitude plan discriminated more. We have no explanation for this finding, other than this variable is capturing something unobserved to us.

To close the native-immigrant unemployment gap integration policies must focus on both supply and demand side factors. On the demand side anti-discrimination legislation must be reinforced and complied with. For example, the integration board could send fictitious applications to job openings periodically in order to ensure equal treatment and bring "criminals" to court as is done in the U.K. 


\section{References:}

Arai, M. and Vilhelmsson, R. (2004) "Unemployment-Risk Differentials Between Immigrant and Native Workers in Sweden", Industrial Relations, 43, p.

Åslund, O. and Rooth, D., (2005) "Do shifts in attitudes affect labour market discrimination: Swedish experiences after 9-11", Journal of Population Economics, 18 (4), pp. 602-629.

Bertrand, M. and Mullainathan, S. (2004) "Are Emily and Greg More Employable Than Lakisha and Jamal? Field Experiment on Labor Discrimination", American Economic Review, pp. 991-1014.

Bovenkerk, F., Gras, M and Ramsoedh, D. (1995) "Discrimination against migrant workers and ethnic minorities in access to employment in the Netherlands", International Migration Papers 4, Geneva, International Labour Office.

Carling, K., Holmlund, B. and Vejsiu, A. (2001) "Do benefit cuts boost job findings? Swedish evidence from the 1990s", The Economic Journal, Vol 111, nr 474, pp. 766790 .

Carlsson, M. (2006), "(No) Evidence on discrimination against females in the Swedish labor market using experimental data", mimeo, Kalmar university.

Carlsson, M. and Rooth, D. (2006), "Evidence of Ethnic Discrimination in the Swedish Labor Market Using Experimental Data”, mimeo, Kalmar university.

Edin, P-A and Lagerström, J. (2004) "Blind Dates: Quasi-Experimental Evidence on Discrimination”, IFAU, Uppsala, Sweden.

FSI (2004) Några frågor om invandringen och invandrare/flyktingar. Forskningsgruppen för Samhälls- och Informationsstudier. Stockholm.

Goldberg, A., Mourinho, D. and Kulke, U. (1996) "Labour market discrimination against foreign workers in Germany" ", International Migration Papers 7, Geneva, International Labour Office.

Heckman, J. (1998), "Detecting discrimination", Journal of Economic Perspectives, 12 , pp 101-16

Lange A (2000) Diskriminering, integration och etniska relationer, Integrationsverket, Norrköping.

le Grand C, Szulkin R (2002) Permanent Disadvantage or Gradual Integration: Explaining the Immigrant-Native Earnings Gap in Sweden. Labour, 16 (1), pp. 3764. 
Mortensen D (1986) Job Search and Labour Market Analysis. In Ashenfelter O, Layard R (ed) Handbook of Labour Economics. Elsevier. Amsterdam, pp. 849-920.

Olli Segendorf, Å. (2005) "Job Search Strategies and Wage Effects for Immigrants", Dissertation 65, Swedish Institute for Social Research, Stockholm University.

Riach, P. A. and Rich, J. (2002), "Field experiments of discrimination in the market place", The Economic Journal, 112, pp. F480-F518

Riach, P. A. and Rich, J. (2004), "Deceptive Field Experiments of Discrimination: Are they Ethical?", Kyklos, 57, pp. 457-470.

Rooth D-O (2002) Adopted Children in the Labour Market - Discrimination or Unobserved Characteristics?. International Migration Quarterly Review, 40 (1), pp. 71-98.

Statistics Sweden (2003), Swedish occupational register, Statistics Sweden, Stockholm

Statistics Sweden (2005), Swedish name register, Statistics Sweden, Stockholm

Weichselbaumer, D. (2003) "Sexual Orientation Discrimination in Hiring", Labour Economics 10 (6), pp. 629-642. 


\section{Tables:}

Table 1. Aggregated results for the correspondence testing

\begin{tabular}{|c|c|c|c|c|c|c|c|c|c|c|}
\hline & \multirow[b]{2}{*}{$\begin{array}{c}\text { Jobs } \\
(1) \\
\text { No. }\end{array}$} & \multirow[b]{2}{*}{$\begin{array}{c}\text { Neither } \\
\text { invited } \\
\text { No. }\end{array}$} & \multirow[b]{2}{*}{$\begin{array}{l}\text { At least } \\
\text { one } \\
\text { invited } \\
(2) \\
\text { No. }\end{array}$} & \multirow[b]{2}{*}{$\begin{array}{c}\text { Equal } \\
\text { treatment } \\
(3) \\
\text { No. }\end{array}$} & \multirow[b]{2}{*}{$\begin{array}{c}\text { Discrimination } \\
\text { against } \\
\text { minority } \\
(4) \\
\text { No. }\end{array}$} & \multirow[b]{2}{*}{$\begin{array}{l}\text { Discrimination } \\
\text { against } \\
\text { majority } \\
(5) \\
\text { No. }\end{array}$} & \multicolumn{4}{|c|}{ Net discrimination } \\
\hline & & & & & & & $\begin{array}{c}(4)-(5) \\
\text { No. }\end{array}$ & $\begin{array}{c}\text { ILO: } \\
{[(4)-(5)] /(2)} \\
\%\end{array}$ & $\begin{array}{c}\text { Ul: } \\
{[(4)-(5)] /(1)} \\
\%\end{array}$ & $\chi^{2}$ \\
\hline Computer professionals & 106 & 71 & 35 & 9 & 14 & 12 & 2 & 5.7 & 1.9 & 0.15 \\
\hline Business Sales & 278 & 164 & 114 & 57 & 39 & 18 & 21 & 18.4 & 7.6 & $7.74^{*}$ \\
\hline Teaching (math and science) a & 42 & 16 & 26 & 17 & 7 & 2 & 5 & 19.2 & 11.9 & 2.78 \\
\hline Preschool Teaching & 184 & 64 & 120 & 76 & 36 & 8 & 28 & 23.3 & 15.2 & $17.82^{*}$ \\
\hline Nursing & 150 & 95 & 55 & 30 & 20 & 5 & 15 & 27.3 & 10.0 & $9.00^{*}$ \\
\hline Teaching (language)a & 60 & 26 & 34 & 9 & 19 & 6 & 13 & 38.2 & 21.7 & $6.76^{*}$ \\
\hline Teaching upper secondary school & 64 & 41 & 23 & 10 & 11 & 2 & 9 & 39.1 & 14.1 & $6.23^{* *}$ \\
\hline Construction & 64 & 44 & 20 & 7 & 12 & 1 & 11 & 55.0 & 17.2 & $9.31^{*}$ \\
\hline Restaurant & 140 & 128 & 12 & 3 & 8 & 1 & 7 & 58.3 & 5.0 & $5.44^{* *}$ \\
\hline Shop Sales & 200 & 167 & 33 & 5 & 24 & 4 & 20 & 60.6 & 10.0 & $14.29^{*}$ \\
\hline Motor-vehicle drivers & 78 & 59 & 19 & 6 & 13 & 0 & 13 & 68.4 & 16.7 & $13.00 *$ \\
\hline Total & 1.614 & 1.087 & 527 & 240 & 221 & 66 & 155 & 29.4 & 9.6 & $83.71^{*}$ \\
\hline
\end{tabular}

Note: The null hypothesis is "Both individuals are treated unfavourable equally often", that is, (4) $=(5)$. The critical value of the $\chi^{2}$ at the one percent level of significance is $6.63\left(^{*}\right)$ and at the five percent level of significance is $3.84(* *)$. (a) Upper level of compulsory school. 
Table 2. Net discrimination. immigrant and female shares and skill requirements on an occupational level

\begin{tabular}{lcccc}
\hline & $\begin{array}{c}\text { Net } \\
\text { Discrimination } \\
(\%)\end{array}$ & $\begin{array}{c}\text { Fraction } \\
\text { Immigrants } \\
(\%)\end{array}$ & $\begin{array}{c}\text { Fraction } \\
\text { Females } \\
(\%)\end{array}$ & $\begin{array}{c}\text { Skill } \\
\text { requirement }\end{array}$ \\
\hline Computer professionals & 5.7 & 8 & 24 & 3 \\
Business Sales & 18.4 & 6 & 38 & 2 \\
Teaching-upper level of compulsory school (Math) & 19.2 & 9 & 76 & 3 \\
Accounting & 22.6 & 7 & 75 & 3 \\
Preschool Teaching & 23.3 & 7 & 92 & 3 \\
Nursing & 27.3 & 10 & 91 & 3 \\
Teaching-upper level of Compulsory school (Lang.) & 38.2 & 9 & 76 & 3 \\
Teaching-upper secondary school & 39.1 & 8 & 53 & 3 \\
Construction & 55.0 & 5 & 1 & 2 \\
Restaurant & 58.3 & 20 & 68 & 1 \\
Shop Sales & 60.6 & 8 & 66 & 2 \\
Motor-vehicle drivers & 68.4 & 12 & 7 & 2 \\
Cleaning & 80.0 & 33 & 80 & 1 \\
\hline Total & 29.4 & 10 & 52 & - \\
\hline
\end{tabular}

Note: Net discrimination is taken from Table 1. Information on the fraction of immigrants and females and on skill requirement in each occupational category is taken from Statistics Sweden (2003). The required skill/level of education in each occupation is defined as $3=$ higher education. $2=$ secondary education and $1=$ primary education.

Table 3. The role of discrimination in the native-immigrant unemployment gap

\begin{tabular}{lcccccc}
\hline & \multicolumn{2}{c}{ All } & \multicolumn{3}{c}{ Higher education } & \multicolumn{2}{c}{ Lower education } \\
& $\mathrm{u}$ & $\varphi$ & $\mathrm{u}$ & $\varphi$ & $\mathrm{u}$ & $\varphi$ \\
\hline Natives (LFS) & 0.039 & 0.29 & 0.032 & 0.36 & 0.042 & 0.22 \\
Immigrants (LFS) & 0.162 & 0.19 & 0.167 & 0.26 & 0.164 & 0.13 \\
Prediction - Immigrants $\left(\mathrm{U}_{\mathrm{N}^{*}} \varphi_{\mathrm{N}} / \varphi_{\mathrm{N}}\right)$ & 0.059 & - & 0.044 & - & 0.071 & - \\
\hline
\end{tabular}

Note: Unemployment rates (u) of natives and immigrants are taken from the Swedish Labour Force Surveys in 2005. $\varphi$ is taken from Table 1 and calculated as the number of times being called for interview divided by the number of job applications. For instance. the call back rate of all natives is calculated as $(240+221) / 1.614=0.29$. For higher (lower) education we calculate $\varphi$ for occupational category $3(1+2)$. The relative call back rate (natives vs. immigrants) is calculated as $0.29 / 0.19=1.53$. $0.36 / 0.26=1.38$ and 1.69 for "all". "higher education" and "lower education". respectively. 
Table 4. Employer characteristics affecting ethnic discrimination in the recruitment process. Probit. marginal effects.

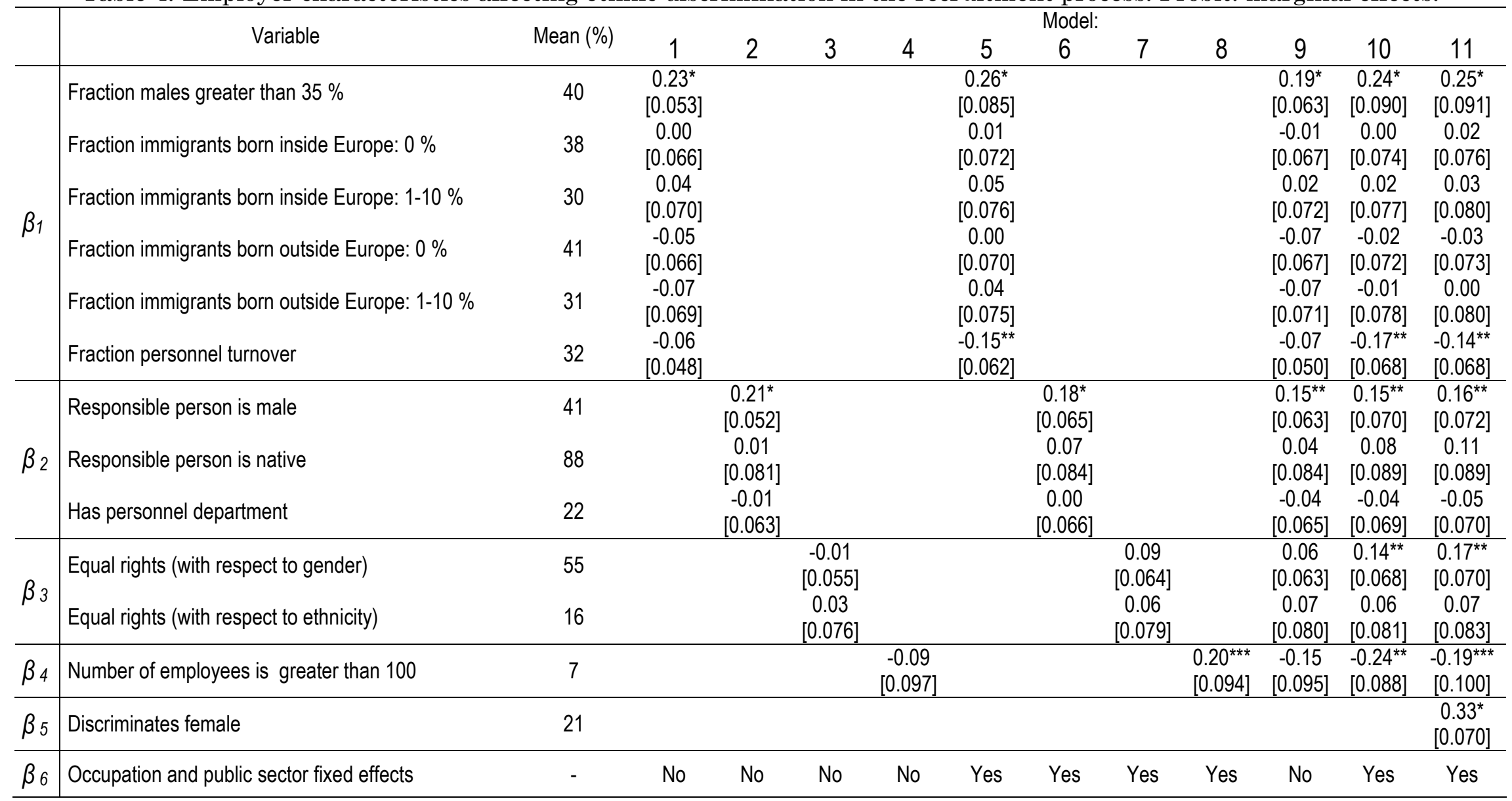

Note: Standard errors in parentheses. $* * *$ and $* * *$ indicates a $<1 \% .<5 \%$ and $<10 \%$ significance level. respectively. A number of interactions have been estimated as well but were not found to be statistically significant. Standard errors adjusted for clustering (on occupation) have also been calculated using the cluster command in STATA. we found negligible impact on the precision of the estimates. 